\title{
THE COMPARISON OF SERRATUS ANTERIOR PLANE BLOCK VERSUS INTERCOSTAL BLOCK FOR POSTOPERATIVE ANALGESIA FOLLOWING THORACOTOMY SURGERY
}

\section{Gözen Öksüz¹, Muhammed Sayan², Mahmut Arslan¹, Aykut Urfalıoğlu¹, Hafize Öksüz¹, Bora Bilal ${ }^{1}$, Oya Yalçın Çok ${ }^{3}$}

${ }^{1}$ Kahramanmaras Sutcu Imam University; School of Medicine, Anesthesiaology Kahramanmaras; Turkey

${ }^{2}$ Gazi University Faculty of Medicine Department of Chest Surgery, Ankara, Turkey

${ }^{3}$ Başkent University Faculty of Medicine, Department of Anesthesiology and Reanimation, Ankara, Turkey

\section{Introduction}

Serratus anterior plane block was described by Blanco et al. in 2013 to provide anesthetic and analgesic blockade of lateral branches of intercostal nerves above and below the serratus anterior muscle.(1) Hence, we aimed to compare serratus anterior plane block (SAPB) with intercostal block (IB) regarding postoperative visual analog scale (VAS) scores for pain and analgesic consumption in patients undergoing thoracotomy operation.

\section{Material and Method}

After approved by local ethics committee patients who underwent thoracotomy operation in our hospital between May 2016 and June 2017 were examined retrospectively. A total of 42 patients were allocated into 2 groups. The patients in group IB received intercostal block and intravenous patient controlled analgesia(PCA) with tramadol, whereas the patients in group SAPB received serratus anterior plane block and PCA with tramadol.

\section{Results}

TABLE 1. Demographic and Clinical Data.

\begin{tabular}{llll}
\hline & SAPB group $(\mathrm{n}=20)$ & IB group $(\mathrm{n}=22)$ & $P$ \\
\hline Age,y & $48,70 \pm 17,061$ & $45,73 \pm 18,846$ & 0,623 \\
\hline Weight,kilo & $68,80 \pm 10,345$ & $73,00 \pm 7,93$ & 0,10 \\
Height,cm & $166,75 \pm 6,904$ & $168,45 \pm 7.701$ & 0,402 \\
Sex.M/F & $9 / 11$ & $13 / 9$ & 0,367 \\
ASA._/II/III & $8 / 9 / 3$ & $8 / 11 / 3$ & 0,890 \\
Operation Time & $159,5 \pm 37,483$ & $154,09 \pm 40,668$ & 0,684
\end{tabular}

ASA; American Society of Anesthesiologist Clasification; SAPB, Serratus anterior plane Block IB, Intercostal Block group.

VAS scores of the patients in the SAPB group were lower than those of the IB group at each time point (Figure 1). The total analgesic use in the first 24 hours postoperatively was significantly lower in the SAPB group as $238.5 \pm 39.5 \mathrm{mg}$ tramadol, compared to $306 \pm 25.2$ mg tramadol in the IB group (Figure 2).

Atelectasis, vomiting, nausea, hypotension, and bradycardia were investigated. No significant difference was determined between the groups in respect of complications
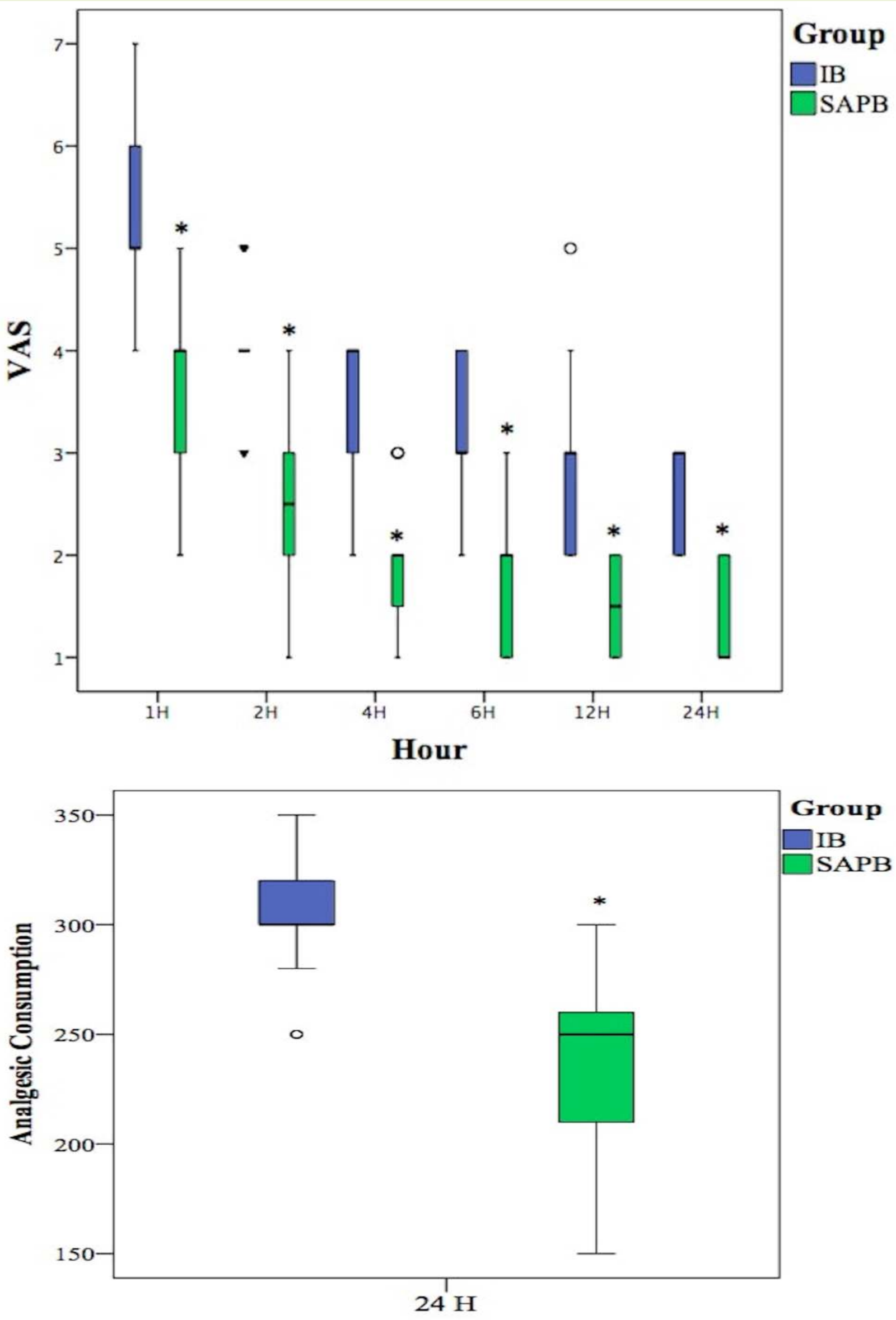

\section{Conclusion}

IB and SAPB may be considered practical analgesia options where paravertebral and epidural block are contraindicated or unnecessarily invasive. However, we suggest that SAPB is more effective and has longer-lasting analgesia than IB following thoracotomy operations.

\section{References}

1.Blanco R, Parras T, McDonnell JG, Prats-Galino A. Serratus plane block: A novel ultrasound-guided thoracic wall nerve block. Anaesthesia. 2013;68(11):1107-1113.

2.Madabushi R, Tewari S, Gautam SK, Agarwal A, Agarwal A. Serratus anterior plane block: a new analgesic technique for postthoracotomy pain. Pain Physician. 2015;20(5): E421-4.

3.Ökmen K, Ökmen BM. The efficacy of serratus anterior plane block in analgesia for thoracotomy: a retrospective study. J Anesth. 2017;31(4): 579-585. 